\title{
Risk of malnutrition in general surgical patients
}

\author{
๑DSümeyye Güzel ${ }^{1}$, @Alev Keser², (1) İlknur Kepenekçi Bayram ${ }^{3}$ \\ ${ }^{1}$ Ankara University, Faculty of Health Sciences, Department of Nutrition and Dietetics, Ankara, Turkey \\ ${ }^{2}$ Ankara University, Faculty of Health Sciences, Department of Nutrition and Dietetics, Ankara, Turkey \\ ${ }^{3}$ Ankara University, İbni Sina Training and Research Hospital, Department of General Surgery, Ankara, Turkey
}

Cite this article as: Güzel S, Keser A, Kepenekçi Bayram İ. Risk of malnutrition in general surgical patients. J Health Sci Med 2021; 4(1): 55-62.

\begin{abstract}
ABSTARCT
Aim: The aim of this study is to determine the malnutrition risk of patients hospitalized in the general surgery clinic and to evaluate the relationship between malnutrition risk and anthropometric measurements.

Material and Method: The study was carried out with 228 adults who were hospitalized in the general surgery clinic. Weight, body mass index (BMI), waist circumference, upper middle arm circumference (MUAC), triceps skinfold thickness (TSF) and handgrip strength measurements were taken. The nutritional status of the patients was evaluated with Nutritional Risk Screening (NRS)-2002 and Subjective Global Assessment (SGA).

Results: According to the NRS-2002, 30.3\% of patients had a risk of malnutrition; according to the SGA $34.2 \%$ had moderate and $12.3 \%$ had severe malnutrition. The anthropometric measurements evaluated in the study and the length of hospital stay (LHOS) were found to be related to the NRS-2002 score and SGA level $(\mathrm{p}<0.05)$. The parameter that most affected the NRS2002 score was MUAC (19.6\%), the LHOS was the most affected by the NRS-2002 score $(8.6 \%)(\mathrm{p}<0.05)$.

Conclusion: The determination of malnutrition risk in general surgery clinics by using practical screening tools such as NRS2002 and SGA and evaluating anthropometric measurements at certain intervals will enable early nutritional support to be initiated, thereby preventing the risk of developing malnutrition and its complications and contributing surgical procedures' success.
\end{abstract}

Keywords: Anthropometric measurements, general surgery, length of hospital stay, malnutrition, Nutritional Risk Screening-2002, Subjective Global Assessment

\section{INTRODUCTION}

Malnutrition, which is an important public health problem for developed and developing countries, occurs with decreased food intake and deterioration in nutritional status, and causes loss of weight in a short time involuntarily $(1,2)$. Nutritional deficiencies are largely due to the direct loss of nutrients, an increase in nutritional requirements and insufficient nutrient consumption required to meet these requirements. However, nutritional problems such as medications, restrictive diets, prolonged hunger, anorexia, nausea and vomiting also contribute to the development of malnutrition (3).

Although malnutrition is common in hospitalized patients, it is an important health problem that is often ignored (4). It has been reported that the prevalence of hospital malnutrition exceeds $70 \%$ in low and middleincome countries and up to $50 \%$ in high-income countries
(5). However, it has been stated that the frequency of malnutrition seen in patients may change between 20$50 \%$ after admission to the hospital, and more weight loss is observed during the initial stay in patients with undernourishment (4). Hospital malnutrition; it causes worsening prognosis, increased risk of developing nosocomial infections, decreased quality of life, prolonged hospital stay, increased morbidity and mortality risk and health expenditures (1). In addition, it has been reported that nutritional support in the early stage improves mucosal atrophy arising from malnutrition and increases anastomotic collagen accumulation and strength (6). Therefore, it is important for patients to have adequate nutritional levels, especially in areas where extensive surgical procedures are applied, to reduce the risk of operative trauma (7). It has been stated that even if the necessary interventions for malnutrition are not performed, even well-performed surgical procedures 
may result in negative results (8-10). In this context, evaluation of nutritional status is important for proper nutrition practices (11). For this reason, many screening and assessment tools have been developed that evaluate nutritional status based on various parameters (12). Among these tools, Nutritional Risk Screening (NRS)2002 and Subjective Global Assessment (SGA) are among the most commonly used tools $(13,14)$. This study was carried out to determine the risk of malnutrition with NRS-2002 and SGA screening tools and to the evaluation of the relationship between malnutrition risk status and anthropometric measurements in adults who were hospitalized in the general surgery clinic.

\section{MATERIAL AND METHOD}

The research is used in accordance with the Helsinki Declaration principles with 228 individuals (aged $\geq 19$ ) who were in the general surgery clinic of Ankara University Research and Training Hospital, who are not bedridden, do not use a pacemaker and are between the ages of 19-90. Ethics Committee Approval which dated 22/05/2018 and numbered 07-449-18 was obtained in order to conduct the research from Ankara University Clinical Research Ethics Committee.

\section{Evaluation of Nutrition}

NRS-2002 and SGA forms were used to evaluate the nutritional status of individuals.Nutritional Risk Screening-2002, which is recommended by the European Society for Clinical Nutrition and Metabolism (ESPEN) for the assessment of nutritional status, is a tool that identifies patients at risk of malnutrition quickly and effectively $(15,16)$. The NRS-2002 scoring system consists of two sections as 'nutritional status' and 'disease severity' and scoring between 0-3 points for each section. Patients with a total score of $\geq 3$ are considered to be at risk of malnutrition (15).

Subjective Global Assessment; is an easy-to-apply and reliable nutritional assessment method based on weight change, change in nutrient intake, gastrointestinal symptoms, functional capacity and physical examination (17). The subjective view of the assessor determines the level of malnutrition. According to this result, individuals are classified into three groups: good nutritional status (SGA-A), moderate nutritional deficiency (SGA-B) and severe malnutrition (SGA-C) (18).

\section{Anthropometric Measurements}

The height of the individuals was determined with Tanita height meter; weight $(\mathrm{kg})$, body fat percentage (BFP,\%), lean body mass (LBM, kg) with Tanita Bc 601 Innerscan body analyzer. In addition, individuals' body mass index (BMI), waist circumference, upper-middle arm circumference (UMAC), triceps skinfold thickness
(TSF) and handgrip strength measurements were taken. However, anthropometric measurements could not be made to the entire study group due to individuals with a lack of physical strength and various limitations. BMI levels of individuals with anthropometric measurements are determined according to WHO criteria (19); UMAC level is based on British Association for Parenteral and Enteral Nutrition (BAPEN) criteria (20), TSF level is based on National Center for Health Statistics (NCHS) percentile values (21), and the handgrip strength is evaluated according to the criteria determined by the study conducted by Dodds et al. (22), which is also used by the European Elderly Sarcopenia Study Group (EWGSOP2) (23). Body mass index $<18.5 \mathrm{~kg} / \mathrm{m} 2$ for both sexes, UMAC $<23.5 \mathrm{~cm}$, TSF $<5$ percentile, handgrip strength $<16 \mathrm{~kg}$ for women, $<27 \mathrm{~kg}$ for men are included in the risk group.

\section{Statistical Analysis of Data}

The analysis of the data was done in SPSS for Windows package program. Descriptive statistics are shown as mean (X) and standard deviation (SD) for variables with normal distribution; median and quartile difference (IQR) values for non-distributed variables; number of cases (n) and percentage (\%) for nominal variables. In the study, statistical analysis between qualitative variables was done using Student's t-test if normal distribution assumptions were provided, and the Mann-Whitney $U$ test if not provided. In terms of a quantitative variable, the difference between the categories of variables with $\geq 3$ categories was evaluated using the One Way ANOVA test if normal distribution assumptions were provided, or the Kruskal Wallis test if not provided. The relationship between the two quantitative variables was evaluated with the Pearson Correlation Coefficient when both variables provided normal distribution assumptions, if at least one of the variables did not provide normal distribution assumptions the Spearman Correlation Coefficient was used. Linear regression analysis was applied to the data with a statistically significant correlation. In all statistical tests, the confidence interval was accepted as $95.0 \%$ and was evaluated at $\mathrm{p}<0.05$ significance level.

\section{RESULTS}

Fifty-two point 2 percent (52.2\%) of the individuals participating in the study are male and $47.8 \%$ are female and the median value of patients' ages is 56.0 (24.0) years. The median value of the length of hospital stay (LHOS) of the patients is 4.0 (8.0) days, and the majority of the reasons for the stay in the general surgery clinic are gastrointestinal tract diseases (63.1\%). Weight loss has been observed in $22.8 \%$ of patients in the last 6 months and the median value of the weight loss percentage is $11.4 \%$ (13.55). Although $25.4 \%$ of individuals expressed 
that their food intake decreased, only $8.8 \%$ stated that they received nutritional support. As a nutritional supplement, enteral nutrition is taken most frequently (65.0\%). According to the NRS-2002 evaluation, 30.3\% of patients have a risk of malnutrition; according to the SGA assessment, $34.2 \%$ had moderate and $12.3 \%$ had severe malnutrition (Table 1).

\begin{tabular}{|c|c|c|}
\hline & $\mathbf{n}$ & $\%$ \\
\hline \multicolumn{3}{|l|}{ Gender } \\
\hline Male & 119 & 52.2 \\
\hline Female & 109 & 47.8 \\
\hline \multicolumn{3}{|l|}{ Reason for hospital stay } \\
\hline Gastrointestinal tract diseases & 144 & 63.2 \\
\hline Endocrine system diseases & 25 & 10.9 \\
\hline Cancer & 23 & 10.1 \\
\hline Non-tumor mass & 23 & 10.1 \\
\hline Other & 13 & 5.7 \\
\hline \multicolumn{3}{|l|}{ Weight loss in the last 6 months } \\
\hline Yes & 52 & 22.8 \\
\hline No & 176 & 77.2 \\
\hline \multicolumn{3}{|l|}{ Change in nutritional intake } \\
\hline Increase & 8 & 3.5 \\
\hline No change & 162 & 71.1 \\
\hline Reduction & 58 & 25.4 \\
\hline \multicolumn{3}{|l|}{ Nutritional support status } \\
\hline Yes & 20 & 8.8 \\
\hline No & 208 & 91.2 \\
\hline Way of nutritional support & - & - \\
\hline Enteral (oral/tube) & 13 & 65.0 \\
\hline Parenterally & 2 & 10.0 \\
\hline Combination & 5 & 25.0 \\
\hline \multicolumn{3}{|l|}{ SGA level } \\
\hline SGA-A & 122 & 53.5 \\
\hline SGA-B & 78 & 34.2 \\
\hline SGA-C & 28 & 12.3 \\
\hline \multicolumn{3}{|l|}{ NRS score } \\
\hline$<3$ & 159 & 69.7 \\
\hline$\geq 3$ & 69 & 30.3 \\
\hline \multicolumn{3}{|l|}{ Age (year) } \\
\hline Median (IQR) & $56.0(24.0)$ & \\
\hline \multicolumn{3}{|c|}{ Percentage of weight loss in the last 6 months (\%) } \\
\hline Median (IQR) & $11.4(13.55)$ & \\
\hline \multicolumn{3}{|l|}{ LHOS (day) } \\
\hline Median (IQR) & $4.0(8.0)$ & \\
\hline
\end{tabular}

Distribution of patients ages, anthropometric measurements, and LOHS by NRS are given in Table 2. According to NRS, compared to those without malnutrition risk, ages and LOHS of patients at risk of malnutrition are statistically significantly higher; weight, BMI, UMAC, TSF, LBM, right and left handgrip strength levels are lower $(\mathrm{p}<0.05)$. However, the percentage of individuals in the risk group for BMI, TSF, left and right handgrip strength is higher among those with an NRS score of $\geq 3(\mathrm{p}<0.05)$ (Table 2$)$.
Distribution of patients ages, anthropometric measurements, and LHOS according to SGA are given in Table 3. There is a statistically significant difference in all parameters evaluated with SGA levels of patients. This difference arising from age, weight, BMI, UMAC, TSF, BFP, left handgrip strength and the LHOS is due to the differences between SGA-A and SGA-B groups, and SGA-C groups; the difference in waist circumference and LBM is due to the differences between SGA-A and SGA-C groups; the difference in right handgrip strength is due to differences between SGA-A and SGA-B groups $(\mathrm{p}<0.05)$. In addition, the rate of individuals in the risk group for BMI, UMAC, TSF, and right handgrip strength was higher in the SGA-C group $(\mathrm{p}<0.05)$ (Table 3).

The correlation of the NRS score, LHOS; ages and anthropometric measurements of the patients are given in Table 4. It was found that a positive correlation between the NRS score and age; a negative correlation between weight, BMI, waist circumference, UMAC, TSF, LBM, left and right handgrip strength $(\mathrm{p}<0.05)$. There was a positive correlation between LHOS, age, and NRS score; a negative correlation between weight, BMI, UMAC, TSF and LBM ( $\mathrm{p}<0.05)$.

Linear regression of parameters with significant correlation in Table 4 is given Table 5. While the NRS score of the patients is mostly explained with UMAC, the LHOS is explained with the NRS score $(\mathrm{p}<0.05)$.

\section{DISCUSSION}

Malnutrition is among the most common health problems in hospitalized patients. Studies in developed countries report that $20-60 \%$ of patients in the hospital are malnourished (24-26). However, malnutrition is associated with medical complications, prolonged recovery time and increased mortality rate. Therefore, identifying patients who are malnourished or at risk of malnutrition is an important requirement for early implementation of nutritional intervention and improving health outcomes (12). While 30.3\% of individuals participating in the research are at risk for malnutrition according to NRS-2002, 34.2\% have moderate malnutrition and $12.3 \%$ have severe malnutrition according to SGA (Table 1). In a study conducted by Ryu and Kim (27) with gastric cancer patients who underwent surgery, it was determined that $43 \%$ of patients had malnutrition risk according to NRS2002 , and $31 \%$ had moderate and severe malnutrition according to SGA. In the research conducted in various clinics by Tangvik et al. (28), the risk of malnutrition was found to be $30.8 \%$ in the general surgery clinic according to NRS-2002. In the study conducted by 
Velasco et al. (29), it was stated that $34.5 \%$ of patients hospitalized in internal medicine and general surgery clinics according to NRS-2002 and $35.3 \%$ of patients according to SGA had malnutrition risk. In the study conducted by Güler and Tireli (30), in which the patients were evaluated with SGA in the general surgery clinic, it was found that $17.3 \%$ of the patients had moderate and severe malnutrition; in the study of Lim et al. (31), it was found that $29 \%$ of the patients had moderate and severe malnutrition. In addition to the burden of the disease for patients hospitalized in surgical clinics, surgery is a stress factor that causes metabolic and physiological changes. In response to stress, basal metabolic rate increases, nitrogen stores are used and negative nitrogen balance may occur. Furthermore, increased intestinal permeability and decreased villi height in the surgical process causes malabsorption and impaired barrier of the intestines against endogenous bacteria and toxins (32). For these reasons, the risk of developing malnutrition in patients hospitalized in the surgical clinic to be high has been confirmed by this and other research results. Given that nutritional deficiencies can directly affect mortality and morbidity in patients undergoing surgical intervention, it is extremely necessary to evaluate the nutritional status of patients in the preoperative period and to plan, implement and monitor early nutritional support when necessary.

Advanced age brings many health-related problems, including malnutrition (33). Many studies have found that malnutrition increases with age $(28,34-36)$. It is stated that compared to younger patients, older individuals use more drugs and have comorbidities that affect their appetite, food intake, and absorption of nutrients. In this context, as elderly individuals show lower tolerance for malnutrition, another score is added to the total score for individuals aged 70 years in the NRS-2002 tool (28). In addition, it has been reported that malnutrition is associated with prolonged hospital stay $(31,37,38)$. In a study conducted by Leandro-Merhi and de Aquino (39), it was determined that the LHOS was extended in case of patients having malnutrition risk according to NRS and advanced malnutrition levels according to SGA. In the study conducted by Wu et al. (40), it was determined that the duration of hospitalization and medical expenses increased with the increase of the SGA score $(\mathrm{p}<0.05)$. In this study, when age and LHOS of the patients were evaluated according to the NRS-2002 score (Table 2) and the SGA level (Table 3), it was found that the NRS score and the SGA level increased statistically significantly with increasing age and LHOS $(\mathrm{p}<0.05)$. The positive correlation of the NRS score with age and LHOS supports these results $(p<0.05)$ (Table 4). According to linear regression analysis, the factor that best explains the LHOS at a statistically significant level is the NRS score $(\mathrm{p}<0.05)$ (Table 5). Patients may have malnutrition at the time of hospitalization, and some of them develop during their stay in the hospital. Therefore, as the LHOS increases, the risk of developing malnutrition increases. Factors such as pain, anxiety, depression, environmental change, different food intake, unusual medication and mealtimes can affect food consumption. Studies show that $30-60 \%$ of food prepared in the hospital is not taken and waste because of meal plans that are not tailored to the needs of patients. For this reason, patients generally receive energy, protein, and micronutrients that are well below their basal needs $(41,42)$. This iatrogenic malnutrition can be largely prevented by appropriate nutrition policies, raising awareness of the healthcare team about malnutrition, screening and patient monitoring at regular intervals.

Anthropometric measurements are important in evaluating the nutritional status as it is an indicator of the amount of adipose tissue and lean body tissue and the distribution of these tissues in the body. In this context; measurements such as weight, BMI, waist circumference, UMAC, skinfold thickness are frequently used methods (43). When the anthropometric measurements of the patients were evaluated according to the NRS2002 score (Table 2) and SGA level (Table 3), in the presence of malnutrition and at the level of increased malnutrition, it was determined that the weight, BMI, UMAC, TSF, LBM, right and left handgrip strength levels of the patients were lower and the ratio of those in the risk group was higher $(\mathrm{p}<0.05)$. However, while the NRS score was negatively correlated with weight, BMI, waist circumference, UMAC, TSF, LBM, left and right handgrip strength; the length of stay in hospital had a negative correlation with weight, BMI, UMAC, TSF and LBM $(\mathrm{p}<0.05)$ (Table 4). According to linear regression analysis, the parameter that most explains the NRS score of the patients is UMAC $(\mathrm{p}<0.05)$ (Table 5). In parallel with the results of this research, in studies nutritional status was evaluated with NRS; it was found that increased NRS score and decreased weight $(44)$, BMI, UMAC $(38,44,45)$, TSF $(38,44)$ values were associated. Likewise, in the studies conducted with SGA, it was determined that the level of weight, BMI $(12,36,40)$, TSF $(36,40)$, UMAC (12), handgrip strength $(12,36)$ decreased and weight loss increased with increasing SGA level. Based on this information, it is thought that anthropometric measurements are a good indicator in the screening and evaluation of malnutrition status, and measurements to be taken at certain intervals may be a guide for nutritional status and disease prognosis. 


\begin{tabular}{|c|c|c|c|c|c|c|}
\hline \multicolumn{7}{|c|}{ NRS score } \\
\hline & \multicolumn{2}{|c|}{$<3(\mathrm{n}: 159)$} & \multicolumn{2}{|c|}{$\geq 3(n: 69)$} & $\mathbf{t} / \mathbf{Z}$ & p \\
\hline Age (year) & \multicolumn{2}{|c|}{$54.0(23.0)$} & \multicolumn{2}{|c|}{$64.0(20.0)$} & -5.077 & $0.000^{*}$ \\
\hline Weight (kg) & \multicolumn{2}{|c|}{$77.7 \pm 13.45$} & \multicolumn{2}{|c|}{$68.6 \pm 12.82$} & 4.182 & $0.000^{*}$ \\
\hline BMI $\left(\mathrm{kg} / \mathrm{m}^{2}\right)$ & \multicolumn{2}{|c|}{$28.1(6.6)$} & \multicolumn{2}{|c|}{$25.5(6.9)$} & -3.603 & $0.000^{*}$ \\
\hline Waist circumference $(\mathrm{cm})$ & \multicolumn{2}{|c|}{$99.8 \pm 12.47$} & \multicolumn{2}{|c|}{$96.9 \pm 11.03$} & 1.589 & 0.114 \\
\hline UMAC $(\mathrm{cm})$ & \multicolumn{2}{|c|}{$31.0(5.0)$} & \multicolumn{2}{|c|}{$28.0(6.0)$} & -4.284 & $0.000^{*}$ \\
\hline TSF $(\mathrm{mm})$ & \multicolumn{2}{|c|}{$23.3(11.6)$} & \multicolumn{2}{|c|}{$17.6(10.4)$} & -3.903 & $0.000^{*}$ \\
\hline BFP (\%) & \multicolumn{2}{|c|}{$30.3 \pm 9.85$} & \multicolumn{2}{|c|}{$27.2 \pm 11.35$} & 1.786 & 0.076 \\
\hline LBM (kg) & \multicolumn{2}{|c|}{$50.3 \pm 10.00$} & \multicolumn{2}{|c|}{$47.0 \pm 7.85$} & 2.379 & $0.018^{*}$ \\
\hline Left handgrip strength (kg) & \multicolumn{2}{|c|}{$20.3(18.0)$} & \multicolumn{2}{|c|}{$17.5(13.8)$} & -2.700 & $0.007^{\star}$ \\
\hline Right handgrip strength $(\mathrm{kg})$ & \multicolumn{2}{|c|}{$21.3(20.0)$} & \multicolumn{2}{|c|}{$17.7(9.2)$} & -2.719 & $0.007^{\star}$ \\
\hline \multirow[t]{2}{*}{ LHOS (day) } & \multicolumn{2}{|c|}{$3.0(4.0)$} & \multicolumn{2}{|c|}{$9.0(11.5)$} & -5.201 & \\
\hline & $\mathbf{n}$ & $\%$ & $\mathbf{n}$ & $\%$ & $\mathbf{X}^{2}$ & $\mathbf{p}$ \\
\hline \multicolumn{7}{|l|}{ BMI $\left(\mathrm{kg} / \mathrm{m}^{2}\right)^{\alpha \beta}(\mathrm{n}: 183)$} \\
\hline Risk group & 1 & 0.8 & 4 & 7.7 & 5.916 & $0.024^{*}$ \\
\hline Non-risk group & 130 & 99.2 & 48 & 92.3 & & \\
\hline \multicolumn{7}{|l|}{ UMAC (cm) ${ }^{\alpha \beta}(\mathbf{n}: 185)$} \\
\hline Risk group & 4 & 3.0 & 4 & 7.5 & 1.692 & 0.193 \\
\hline Non-risk group & 128 & 97.0 & 49 & 92.5 & & \\
\hline \multicolumn{7}{|l|}{ TSF $(\mathbf{c m})^{\alpha \beta}(\mathbf{n}: 185)$} \\
\hline Risk group & 4 & 3.0 & 7 & 13.2 & 6.204 & $0.013^{*}$ \\
\hline Non-risk group & 128 & 97.0 & 46 & 86.8 & & \\
\hline \multicolumn{7}{|c|}{ Left handgrip strength ${ }^{{ }^{\alpha} \gamma}$ (n:183) } \\
\hline Risk group & 58 & 36.5 & 39 & 75.0 & 14.107 & $0.000^{*}$ \\
\hline Non-risk group & 73 & 45.9 & 13 & 25.0 & & \\
\hline \multicolumn{7}{|c|}{ Right handgrip strength ${ }^{\alpha \gamma}$ (n:184) } \\
\hline Risk group & 55 & 41.7 & 35 & 67.3 & 9.815 & $0.002^{*}$ \\
\hline
\end{tabular}

\begin{tabular}{|c|c|c|c|c|c|c|c|c|}
\hline 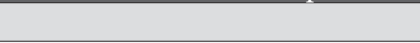 & \multicolumn{2}{|c|}{ SGA-A $^{1}(\mathrm{n}: 122)$} & \multicolumn{2}{|c|}{ SGA-B $^{2}(\mathrm{n}: 78)$} & \multicolumn{2}{|c|}{ SGA-C $(\mathbf{n}: 28)$} & $t / Z$ & $\mathbf{p}$ \\
\hline Age (year) ${ }^{1-2,1-3}$ & \multicolumn{2}{|c|}{$52.0(19.25)$} & \multicolumn{2}{|c|}{$64.0(21.7)$} & \multicolumn{2}{|c|}{$64.5(31.5)$} & 35.028 & $0.000^{*}$ \\
\hline Weight $(\mathrm{kg})^{1-2,1-3}$ & \multicolumn{2}{|c|}{$80.3 \pm 12.31$} & \multicolumn{2}{|c|}{$69.7 \pm 12.80$} & \multicolumn{2}{|c|}{$63.3 \pm 12.70$} & 21.633 & $0.000^{*}$ \\
\hline BMI $\left(\mathrm{kg} / \mathrm{m}^{2}\right)^{1-2,1-3}$ & \multicolumn{2}{|c|}{$28.7(6.6)$} & \multicolumn{2}{|c|}{$25.7(5.3)$} & \multicolumn{2}{|c|}{$21.9(8.5)$} & 30.074 & $0.000^{*}$ \\
\hline Waist circumference $(\mathrm{cm})^{1-3}$ & \multicolumn{2}{|c|}{$101.3 \pm 12.29$} & \multicolumn{2}{|c|}{$97.1 \pm 10.97$} & \multicolumn{2}{|c|}{$91.6 \pm 12.16$} & 5.882 & $0.003^{*}$ \\
\hline UMAC $(\mathrm{cm})^{1-2,1-3}$ & \multicolumn{2}{|c|}{$32.0(5.0)$} & \multicolumn{2}{|c|}{$29.0(5.0)$} & \multicolumn{2}{|c|}{$25.0(5.2)$} & 43.958 & $0.000^{*}$ \\
\hline $\operatorname{TSF}(\mathrm{mm})^{1-2,1-3}$ & \multicolumn{2}{|c|}{$24.9 \pm 7.43$} & \multicolumn{2}{|c|}{$19.8 \pm 6.57$} & \multicolumn{2}{|c|}{$16.1 \pm 6.78$} & 18.074 & $0.000^{*}$ \\
\hline $\operatorname{BFP}(\%)^{1-2,1-3}$ & \multicolumn{2}{|c|}{$31.5 \pm 9.71$} & \multicolumn{2}{|c|}{$27.5 \pm 10.00$} & \multicolumn{2}{|c|}{$23.5 \pm 13.06$} & 5.728 & $0.004^{\star}$ \\
\hline $\operatorname{LBM}(\mathrm{kg})^{1-3}$ & \multicolumn{2}{|c|}{$51.0 \pm 9.91$} & \multicolumn{2}{|c|}{$47.4 \pm 8.73$} & \multicolumn{2}{|c|}{$47.2 \pm 8.48$} & 3.685 & $0.027^{*}$ \\
\hline Left handgrip strength $(\mathrm{kg})^{1-2,1-3}$ & \multicolumn{2}{|c|}{$22.2(16.8)$} & \multicolumn{2}{|c|}{$17.4(14.2)$} & \multicolumn{2}{|c|}{$14.6(11.2)$} & 11.952 & $0.003^{*}$ \\
\hline Right handgrip strength $(\mathrm{kg})^{1-2}$ & \multicolumn{2}{|c|}{$23.3(20.1)$} & & & & & 12.033 & $0.002^{*}$ \\
\hline LHOS (gün) $)^{1-2,1-3}$ & & & & & & & 32.025 & $0.000^{*}$ \\
\hline & $\mathbf{n}$ & $\%$ & n & $\%$ & $\mathbf{n}$ & $\%$ & $\mathrm{X} 2$ & p \\
\hline BMI (kg/m2) a $\beta(\mathrm{n}: 183)$ & & & & & & & & \\
\hline Risk group & - & - & 2 & 3.1 & 3 & 20.0 & 6.725 & $0.024^{*}$ \\
\hline Non-risk group & 103 & 100.0 & 63 & 96.9 & 12 & 80.0 & & \\
\hline UMAC (cm) $\alpha \beta(\mathrm{n}: 185)$ & & & & & & & & \\
\hline Risk group & 1 & 1.0 & 4 & 6.1 & 3 & 20.0 & 9.877 & $0.004^{\star}$ \\
\hline Non-risk group & 103 & 99.0 & 62 & 93.9 & 12 & 80.0 & & \\
\hline TSF (cm) $\alpha \beta(n: 185)$ & & & & & & & & \\
\hline Risk group & 2 & 1.9 & 5 & 7.6 & 4 & 26.7 & 11.386 & $0.002^{*}$ \\
\hline Non-risk group & 102 & 98.1 & 61 & 92.4 & 11 & 73.3 & & \\
\hline Left handgrip strength $\alpha \gamma$ (n:183 & & & & & & & & \\
\hline Risk group & 40 & 38.5 & 45 & 70.3 & 12 & 38.5 & 20.915 & $0.000^{*}$ \\
\hline Non-risk group & 64 & 61.5 & 19 & 29.7 & 3 & 61.5 & & \\
\hline Right handgrip strength $\alpha \gamma$ (n:1 & & & & & & & & \\
\hline Risk group & 38 & 36.5 & 41 & 63.1 & 11 & 73.3 & 15.171 & $0.001^{*}$ \\
\hline Non-risk group & 66 & 63.5 & 24 & 36.9 & 4 & 26.7 & & \\
\hline
\end{tabular}




\begin{tabular}{|c|c|c|c|c|}
\hline & \multicolumn{2}{|c|}{$\begin{array}{l}\text { Correlation with } \\
\text { NRS score }\end{array}$} & \multicolumn{2}{|c|}{$\begin{array}{c}\text { Correlation with } \\
\text { LHOS }\end{array}$} \\
\hline & $\mathbf{r}$ & p & $\mathbf{r}$ & $\mathbf{p}$ \\
\hline Age (year) & 0.428 & $0.000^{*}$ & 0.143 & $0.031^{*}$ \\
\hline Weight (kg) & -0.411 & $0.000^{*}$ & -0.188 & $0.011^{*}$ \\
\hline $\operatorname{BMI}\left(\mathrm{kg} / \mathrm{m}^{2}\right)$ & -0.342 & $0.000^{*}$ & -0.161 & $0.029^{*}$ \\
\hline $\begin{array}{l}\text { Waist circumference } \\
(\mathrm{cm})\end{array}$ & -0.153 & $0.038^{*}$ & -0.062 & 0.398 \\
\hline UMAC $(\mathrm{cm})$ & -0.453 & $0.000^{*}$ & -0.194 & $0.008^{*}$ \\
\hline TSF (mm) & -0.351 & $0.000^{*}$ & -0.212 & $0.004^{\star}$ \\
\hline BFP (\%) & -0.143 & 0.054 & -0.010 & 0.892 \\
\hline LBM (kg) & -0.249 & $0.001^{*}$ & -0.208 & $0.005^{\star}$ \\
\hline $\begin{array}{l}\text { Left handgrip } \\
\text { strength (kg) }\end{array}$ & -0.291 & $0.000^{*}$ & -0.108 & 0.144 \\
\hline $\begin{array}{l}\text { Right handgrip } \\
\text { strength }(\mathrm{kg})\end{array}$ & -0.290 & $0.000^{*}$ & -0.116 & 0.115 \\
\hline NRS score & - & - & 0.407 & $0.000^{*}$ \\
\hline
\end{tabular}

Table 5. Linear regression of patients' NRS score and LHOS; ages and anthropometric measurements

\begin{tabular}{|c|c|c|c|c|c|}
\hline & B & $\% 95$ (CI) & $\beta$ & $\mathbf{R}^{2}$ & $\mathbf{p}$ \\
\hline \multicolumn{6}{|c|}{ Regression with NRS score } \\
\hline Age (year) & 0.043 & $\begin{array}{c}0.030- \\
0.056\end{array}$ & 0.396 & 0.157 & $0.000^{*}$ \\
\hline Weight (kg) & -0.053 & $\begin{array}{l}-0.069- \\
-0.036\end{array}$ & -0.432 & 0.187 & $0.000^{*}$ \\
\hline $\operatorname{BMI}\left(\mathrm{kg} / \mathrm{m}^{2}\right)$ & -0.102 & $\begin{array}{l}-0.143- \\
-0.062\end{array}$ & -0.350 & 0.123 & $0.000^{*}$ \\
\hline $\begin{array}{l}\text { Waist } \\
\text { circumference } \\
(\mathrm{cm})\end{array}$ & -0.026 & $\begin{array}{c}-0.046- \\
-0.010\end{array}$ & -0.188 & 0.035 & $0.010^{*}$ \\
\hline $\mathrm{UMAC}(\mathrm{cm})$ & -0.176 & $\begin{array}{l}-0.228- \\
-0.124\end{array}$ & -0.442 & 0.196 & $0.000^{*}$ \\
\hline TSF (mm) & -0.082 & $\begin{array}{l}-0.112- \\
-0.053\end{array}$ & -0.377 & 0.142 & $0.000^{*}$ \\
\hline LBM $(\mathrm{kg})$ & -0.041 & $\begin{array}{l}-0.066- \\
-0.016\end{array}$ & -0.236 & 0.056 & $0.001^{*}$ \\
\hline $\begin{array}{l}\text { Left handgrip } \\
\text { strength (kg) }\end{array}$ & -0.044 & $\begin{array}{l}-0.067- \\
-0.022\end{array}$ & -0.275 & 0.076 & $0.000^{*}$ \\
\hline $\begin{array}{l}\text { Right handgrip } \\
\text { strength (kg) }\end{array}$ & -0.042 & $\begin{array}{l}-0.063- \\
-0.021\end{array}$ & -0.282 & 0.080 & $0.000^{*}$ \\
\hline \multicolumn{6}{|c|}{ Regression with LHOS } \\
\hline Age (year) & 0.038 & $\begin{array}{l}-0.051- \\
-0.128\end{array}$ & 0.056 & 0.003 & 0.399 \\
\hline Weight $(\mathrm{kg})$ & -0.075 & $\begin{array}{c}-0.190- \\
0.040\end{array}$ & -0.095 & 0.009 & 0.202 \\
\hline BMI $\left(\mathrm{kg} / \mathrm{m}^{2}\right)$ & 0.035 & $\begin{array}{c}-0.243- \\
0.312\end{array}$ & 0.018 & 0.000 & 0.806 \\
\hline UMAC (cm) & -0.119 & $\begin{array}{c}-0.495- \\
0.256\end{array}$ & -0.046 & 0.002 & 0.531 \\
\hline $\mathrm{TSF}(\mathrm{mm})$ & -0.112 & $\begin{array}{l}-0.317- \\
0.094\end{array}$ & -0.079 & 0.006 & 0.286 \\
\hline LBM (kg) & -0.245 & $\begin{array}{l}-0.409- \\
-0.080\end{array}$ & 0.214 & 0.046 & $0.004^{*}$ \\
\hline NRS score & 1.867 & $\begin{array}{l}1.071- \\
2.662\end{array}$ & 0.294 & 0.086 & $0.000^{\star}$ \\
\hline
\end{tabular}

\section{CONCLUSION}

The rate of malnutrition in patients hospitalized in the general surgery clinic is quite high. In surgical patients, delaying the postoperative oral intake for more than seven days, not starting early nutritional support, not understanding the increasing nutritional requirements, and not being able to provide perioperative nutritional support in the patient with impaired nutrition are important factors in the development of malnutrition. Malnutrition causes deterioration of disease prognosis, increased susceptibility to infections, prolonged hospital stay, increased unnecessary treatment expenditures, resulting in significant economic losses and an increase in morbidity and mortality rates. In order to protect against malnutrition, which is a common but preventable condition, it is an important requirement that raising awareness of patients and training involving healthy nutrition, developing and implementing diseasespecific nutrition guides, screening and monitoring the nutritional status of risky groups systematically, and providing adequate and balanced nutrition principles as part of the basic and vocational training of all health personnel. Nutritional support to be provided in the early period will help to improve inflammatory and metabolic responses after surgery and reduce the risk of postoperative complications. In this context, in clinics with a high risk of malnutrition, it is essential to have Nutritional Support Teams and provide nutritional support to patients as soon as possible.

\section{ETHICAL DECLARATIONS}

Ethics Committee Approval: The study protocol was approved by the Ethics Committee Approval which dated 22/05/2018 and numbered 07-449-18 was obtained from Ankara University Clinical Research Ethics Committee.

Informed Consent: All patients signed the free and informed consent form.

Referee Evaluation Process: Externally peer-reviewed.

Conflict of Interest Statement: The authors have no conflicts of interest to declare.

Financial Disclosure: The authors declared that this study has received no financial support.

Author Contributions: All of the authors declare that they have all participated in the design, execution, and analysis of the paper, and that they have approved the final version. 


\section{REFERENCES}

1. Suárez-Llanos JP, Benítez-Brito N, Vallejo-Torres L, et al. Clinical and cost-effectiveness analysis of early detection of patients at nutrition risk during their hospital stay through the new screening method CIPA: A Study Protocol. BMC Health Serv Res 2017; 17: 292.

2. Correia MI, Peman MI, Waitzberg DL. Hospital malnutrition in Latin America: a systematic review. Clin Nutr 2017; 36: 958-67.

3. Bucay AJ, Machiavelo MA, Alvarez-Altamirano K, et al. Hospital malnutrition: food services need to be improved in Mexico. Int J Clin Nutr 2017; 1: 13-7.

4. Weiss ARR, Wassermann U, Brennfleck F, et al. Prevalence of malnutrition in general surgery applying the nutritional risk screening 2002. J Surg Pract 2018; 1: 5.

5. Nakahara S, Nguyen DH, Bui AT, et al. Perioperative nutrition management as an important component of surgical capacity in low - and middle - income countries. Trop Med Int Health 2017; 22: 784-96.

6. Tang Z, Cai H, Cui Y. Influence of early postoperative feeding in gastrointestinal anastomotic fistula formation and healing time in rabbits. Biomed Res Int 2018; 2018: 8258096.

7. Horowitz M, Neeman E, Sharon E, et al. Exploiting the critical perioperative period to improve long-term cancer outcomes. Nat Rev Clin Oncology 2015; 12: 213-26.

8. Starke J, Schneider H, Alteheld B, et al. Short-term individual nutritional care as part of routine clinical setting improves outcome and quality of life in malnourished medical patients. Clin Nutr 2011; 30: 194-201.

9. Yeh DD, Fuentes E, Quraishi SA, et al. Adequate nutrition may get you home: effect of caloric/protein deficits on the discharge destination of critically ill surgical patients. J Parent Enteral Nutr 2016; 40: 37-44.

10.Zhong JX, Kang K, Shu XL. Effect of nutritional support on clinical outcomes in perioperative malnourished patients: A meta-analysis. Asia Pac J Clin Nutr 2015; 24: 367-78.

11. Mueller C, Compher C, Ellen DM. A.S.P.E.N. clinical guidelines: nutrition screening, assessment, and intervention in adults. Parent Enteral Nutr 2011; 35: 16-24.

12. Flood A, Chung A, Parker H, et al. The use of handgrip strength as a predictor of nutrition status in hospital patients. Clin Nutr 2014; 33: 106-14.

13.Lomivorotov VV, Efremov SM, Boboshko VA, et al. Evaluation of nutritional screening tools for patients scheduled for cardiac surgery. Nutr 2013; 29: 436-42.

14.Lomivorotov VV, Efremov SM, Boboshko VA, et al. Prognostic value of nutritional screening tools for patients scheduled for cardiac surgery. Interact Cardiovasc Thorac Surg 2013; 16: 612-8.

15. Kondrup J, Allison SP, Elia M, et al. ESPEN guidelines for Nutrition Screening 2002. Clin Nutr 2003; 22: 415-21.

16. Alhaugi J, Gay CL, Henriksen C, et al. Pressure ulcer is associated with malnutrition as assessed by Nutritional Risk Screening (NRS 2002) in a mixed hospital population. Food Nutr Res 2017; 61: 1324230 .

17. Bauer J, Capra S, Ferguson M. Use of the scored patient-generated Subjective Global Assessment (PG-SGA) as a nutrition assessment tool in patients with cancer. Eur J Clin Nutr 2002; 56: 779-85.

18. Gupta D, Lammersfeld CA, Vashi PG, et al. Prognostic significance of Subjective Global Assessment (SGA) in advanced colorectal cancer. Eur J Clin Nutr 2005; 59: 35-40.

19. WHO. Waist Circumference and Waist-Hip Ratio: Report of a WHO Expert Consultation. http://apps. who. int/iris/ bitstream/10665/44583/1/9789241501491_eng. pdf. Accessed April 6, 2017.

20.BAPEN. Malnutrition Universal Screening Tool. https://www. bapen. org. uk/pdfs/must/must_full. pdf. Accessed March 9, 2020.
21. Bishop CW, Bowen PE, Ritchey SJ. Norms for nutritional assessment of American adults by upper arm anthropometry. Am J Clin Nutr 1981; 34: 2530-9.

22.Dodds RM, Syddall HE, Cooper R, et al. Grip Strength across the life course: normative data from twelve British studies. PLoS One 2014; 9: e113637.

23. Cruz-Jentoft AJ, Bahat G, Bauer J, et al. Sarcopenia: revised European consensus on definition and diagnosis. Age Ageing 2019; 48: 16-31.

24. Correia MI, Waitzberg DL. The impact of malnutrition on morbidity, mortality, length of hospital stay and costs evaluated through a multivariate model analysis. Clin Nutr 2003; 22: 235-9.

25. Norman K, Schütz T, Kemps M, Josef Lübke H, Lochs H, Pirlich M. The Subjective Global Assessment reliably identifies malnutritionrelated muscle dysfunction. Clin Nutr 2005; 24: 143-50.

26. Westergren A, Torfadóttir O, Ulander K, et al. Malnutrition prevalence and precision in nutritional care: an intervention study in one teaching hospital in Iceland. J Clin Nurs 2010; 19: 1830-37.

27. Ryu W, Kim H. Comparison of different nutritional assessments in detecting malnutrition among gastric cancer patients. World J Gastroenterol 2010; 16: 3310-7.

28. Tangvik RJ, Tell GS, Guttormsen AB, et al. Nutritional risk profile in a university hospital population. Clin Nutr 2015; 34: 705-11.

29. Valesco C, Garcia EV, Rodríguez V, et al. Comparison of four nutritional screening tools to detect nutritional risk in hospitalized patients: a multicentre study. Eur J Clin Nutr 2011; 65: 269-74.

30. Guler Y, Tireli M. Malnutrition frequency in surgical patients and its effect on morbidity and mortality. Acta Medica Alanya 2018; 2: 35-9.

31.Lim SL, Ong KC, Chan YH, et al. Malnutrition and its impact on cost of hospitalization, length of stay, readmission and 3-year mortality. Clin Nutr 2012; 31: 345-50.

32. Abunnaja S, Cuviello A, Sanchez JA. Enteral and parenteral nutrition in the perioperative period: state of the art. Nutrients 2013; 5: 608-23.

33.Leij-Halfwerk S, Verwijs MH, van Houdt S, et al. Prevalence of protein-energy malnutrition risk in European older adults in community, residential and hospital settings, according to 22 malnutrition screening tools validated for use in adults $\geq 65$ years: A systematic review and meta-analysis. Maturitas 2019; 126: 80-9.

34. Imoberdorf R, Meier R, Krebs P, et al. Prevalence of undernutrition on admission to Swiss hospitals. Clin Nutr 2010; 29: 38-41.

35. Kyle UG, Kossovsky MP, Karsegard VL, et al. Comparison of tools for nutritional assessment and screening at hospital admission: a population study. Clin Nutr 2006; 25: 409-17.

36. Pham NV, Cox-Reijven PL, Wodzig WK, et al. SGA and measures for muscle mass and strength in surgical Vietnamese patients. Nutr 2007; 23: 283-91.

37. Agarwal E, Ferguson M, Banks M, et al. Malnutrition and poor food intake are associated with prolonged hospital stay, frequent readmissions, and greater in-hospital mortality: results from the Nutrition Care Day Survey 2010. Clin Nutr 2013; 32: 737-45.

38. Knappe-Drzikova B, Maasberg S, Vonderbeck D, et al. Malnutrition predicts long-term survival in hospitalized patients with gastroenterological and hepatological diseases. Clin Nutr ESPEN 2019; 30: 26-34.

39.Leandro-Merhi VA, Braga de Aquino JL. Comparison of nutritional diagnosis methods and prediction of clinical outcomes in patients with neoplasms and digestive tract diseases. Clin Nutr 2015; 34: 647-51.

40. Wu B, Yin TT, Cao W, et al. Validation of the Chinese version of the Subjective Global Assessment scale of nutritional status in a sample of patients with gastrointestinal cancer. Int J Nurs Stud 2010; 47: 323-31. 
41.Hiesmayr M, Schindler K, Pernicka E, et al. Decreased food intake is a risk factor for mortality in hospitalised patients: the NutritionDay survey 2006. Clin Nutr 2009; 28: 484-91.

42. Naber TH, Schermer T, de Bree A, et al. Prevalence of malnutrition in nonsurgical hospitalized patients and its association with disease complications. Am J Clin Nutr 1997; 66: 1232-9.

43. Pekcan G. Determination of nutritional status. Republic of Turkey Ministry of Health Publication Nu: 726, Ankara; 2008.

44. Maasberg S, Knappe-Drzikova B, Vonderbeck D, et al. Malnutrition predicts clinical outcome in patients with neuroendocrine neoplasia. Neuroendocrinology 2017; 104: 11-25.

45. Turkoglu I, Ilgaz A, Yalcin T, et al. Prevalence of malnutrition in hospitalized adult patients: a comparison of four nutritional screening tools. J Nutr Diet 2015; 43: 135-42. 